\title{
Studies of the Volatile Compounds Present in Leaves, Stems and Flowers of Vernonanthura patens (Kunth) H. Rob
}

\author{
Patricia Manzano, ${ }^{12^{*}}$, Migdalia Miranda', Tulio Orellana', Maria Quijano' \\ ${ }^{1}$ Superior Polytechnic School of Litoral, Biotechnology Research Center of Ecuador (ESPOL-CIBE), Guayaquil, \\ Ecuador \\ ${ }^{2}$ Faculty of Natural Sciences and Mathematics of Superior Polytechnic School of Litoral, Guayaquil, Ecuador \\ Email: " manzanopatricial@hotmail.com, ${ }^{*}$ pmanzano@espol.edu.ec
}

Received 15 October 2014; revised 30 November 2014; accepted 16 December 2014

Copyright (C) 2014 by authors and Scientific Research Publishing Inc.

This work is licensed under the Creative Commons Attribution International License (CC BY). http://creativecommons.org/licenses/by/4.0/

(c) (†) Open Access

\section{Abstract}

The study of the volatile components of the leaves, stems and flowers of Vernonanthura patens is discussed. A micro solid-phase extraction at constant temperature with a dimethylsiloxane fiber of $100 \mu \mathrm{m}$ was performed. The compounds extracted were analyzed by gas chromatography coupled to mass spectrometry (GC-MS). 7 monoterpenes structures were assigned to leaves, and three to stems, these compounds were not detected in the flowers with the configuration of the system used. 17 sesquiterpenes were identified in the leaves; 6 in stems and 2 in flowers, finding coincidence in some of them. The major components were $\alpha$-humulene in leaves, bergamotene in stems and caryophyllene in flowers.

\section{Keywords}

V. patens, Volatile, Bergamotene, Caryophyllene, $\alpha$-Humulene

\section{Introduction}

Asteraceae (Asteraceae), gather more than 23,500 species spread over about 1600 genera, so the family of Angiosperms is rich and biological diversity [1] [2]. Members of this family are distributed from Polar Regions to the tropics, conquering all available habitats, from dry deserts to swamps and from forests to mountain peaks. In many regions, this family reaches up to $10 \%$ of vernacular flora and contains some genera with a large number of species, as Vernonia (Vernonanthura), with more than 1000 species [3]. Many species have latex and essen-

\footnotetext{
${ }^{*}$ Corresponding author.

How to cite this paper: Manzano, P., Miranda, M., Orellana, T. and Quijano, M. (2014) Studies of the Volatile Compounds Present in Leaves, Stems and Flowers of Vernonanthura patens (Kunth) H. Rob. International Journal of Organic Chemistry, 4, 314-318. http://dx.doi.org/10.4236/ijoc.2014.45034
} 
tial oils and may or may not be resinous.

Vernonanthura patens is an Asteraceae that grows wild in Ecuador and is employed by people of the Ecuadorian coast to cure various conditions. Manzano et al. have reported that alcoholic extracts of the leaves show "in vitro" antileishmanial activity against Leihsmania amazonensis [4].

Studies conducted on the chemical composition of the species of the Ecuadorian coast have reported the presence of some terpene compounds (mainly pentacyclic triterpenoids), diterpenoids and sesquiterpenoids [5]. Those last are a part of the volatile fraction of the species and not essential oils which are presented in appreciable conditions so this work is carried out to study the volatile components obtained by solid phase micro extraction (SPME) at constant temperature $\left(50^{\circ} \mathrm{C}\right)$ with a fiber of 100 microns dimethylsiloxane.

\section{Materials and Methods}

Leaves, flowers and stems of the species in phenological stage of flowering, collected around the Biotechnology Research Center of Ecuador located at Km 30.5 via Perimeter province of Guayas-Ecuador, were used. A sample of the plant material was taken for botanical identification which was botanized at the National Herbarium of Ecuador (QCNE), Quito, with CIBE37a code.

The volatile compounds were obtained by solid phase microextraction (SPME) at constant temperature of $50^{\circ} \mathrm{C}$ with a fiber of 100 microns dimethylsiloxane.

The chemical composition of the volatile compounds was analyzed in a gas chromatograph connected to a mass spectrometer (GC-MS) Agilent Technologies, equipped with a J \& W capillary column GC of $30 \times 250$ microns $\times 0.25$. The conditions were as follows: initial temperature in the oven $60^{\circ} \mathrm{C}$ for 1 minute to $260^{\circ} \mathrm{C}$ with an increment of $5^{\circ} \mathrm{C}$ per minute; followed by an increase of $15^{\circ} \mathrm{C}$ per min to $300^{\circ} \mathrm{C}$ for 1 minute. Temperatures for injector and detector were $150^{\circ} \mathrm{C}$ and $280^{\circ} \mathrm{C}$, respectively in split mode. The volatiles compounds were assigned by comparison of their spectra with reference compounds existing in the Wiley and Nist library ninth edition 2011 installed on the computer.

\section{Results and Discussion}

Chromatograms of the volatile compounds from leaves, stems and flowers of $V$. patens is shown in Figure 1; the chromatogram of the volatile compounds from the leaves was the most complex and the chromatogram of the flowers was less complex. It is noteworthy that most of the major components are in the range of retention times between 15 and 20 min. Between 20 and 25 min., only the leaves had components with relative abundance. Moreover, the presence of a compound with high relative abundance correspond to the sesquiterpene caryophyllene with a retention time of 18.2 min approximately. This compound had been identified for the leaves of the Ecuadorian species [5] and Vernonia ssp [6].

Table 1 shows the monoterpenes isolated from different plant organs.

It is appreciated that the leaves had a higher number of monoterpene compounds, with a total of seven while in the stems were identified three. In the flowers these compounds could not be detected, or were absent.

Monoterpene compounds eluted from the column between the minutes 5.5 and 8.5 of the run. Retention time

Table 1. Monoterpenes identified in the fraction of volatile compounds of $V$. patens.

\begin{tabular}{|c|c|c|c|c|c|}
\hline \multicolumn{3}{|c|}{ leaves } & \multicolumn{3}{|c|}{ steams } \\
\hline $\begin{array}{c}\text { tr } \\
\text { min }\end{array}$ & compounts & $\%$ abund & tr & compounts & $\%$ abund \\
\hline 5.66 & $\alpha$-pinene & 0.27 & - & - & - \\
\hline 6.50 & sabinene & 0.23 & - & - & - \\
\hline 6.59 & $\beta$-pinene & 3.32 & - & - & - \\
\hline 6.86 & $\beta$-myrcene & 0.39 & - & - & - \\
\hline 7.70 & p-cymene & 0.66 & 7.70 & p-cymene & 3.01 \\
\hline 7.81 & D-limonene & 0.85 & 7.81 & D-limonene & 7.41 \\
\hline 8.25 & $\beta$-ocimeno & 0.76 & 8.25 & $\beta$-ocimeno & 6.46 \\
\hline
\end{tabular}




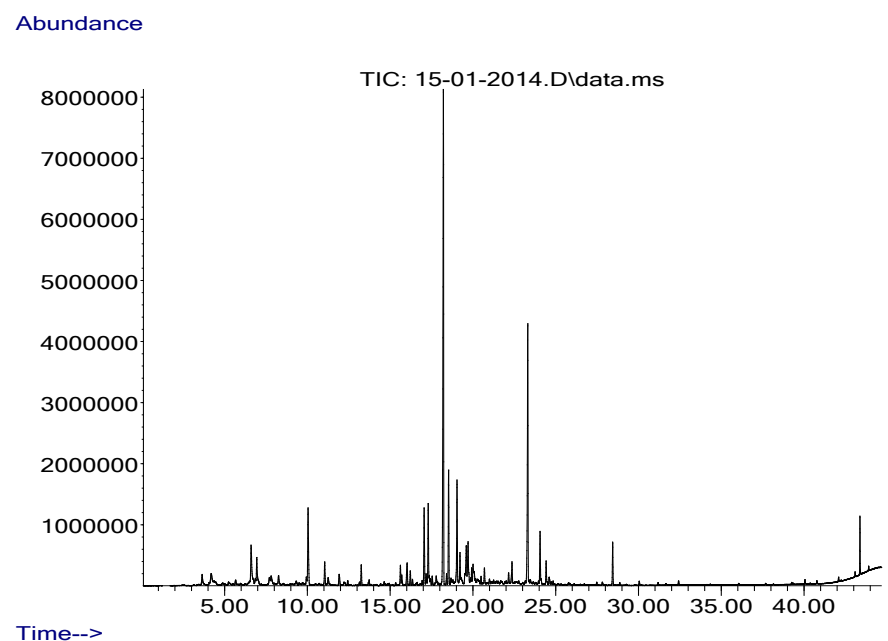

(a)

Abundance

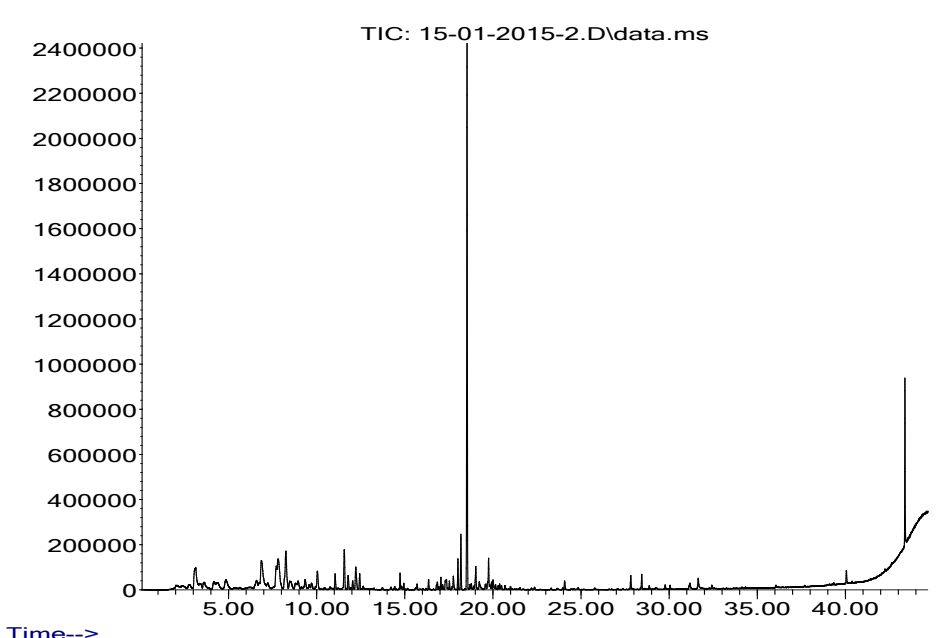

(b)

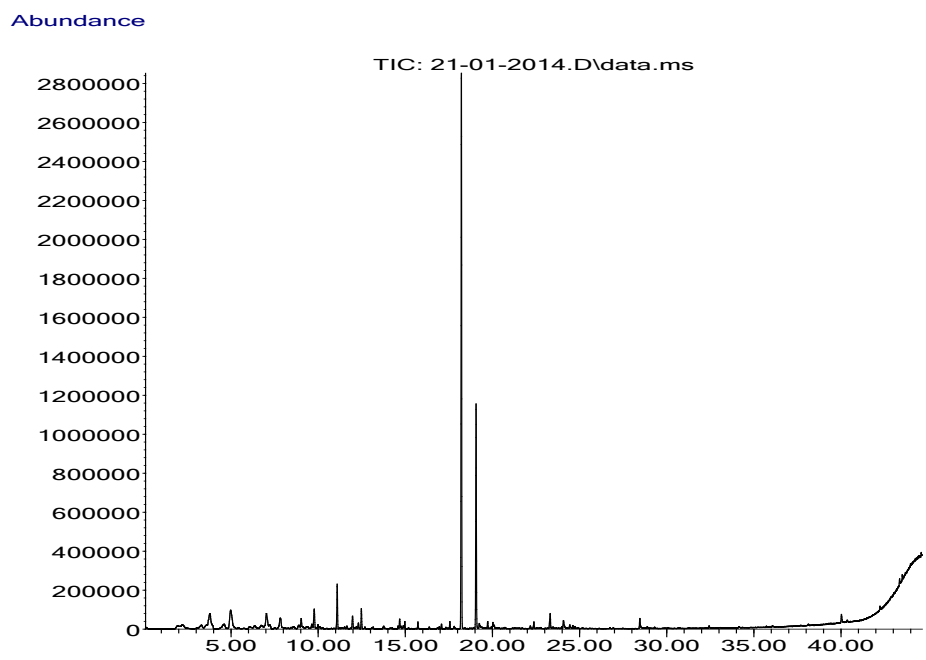

(c)

Figure 1. Analytic gas chromatograms of volatile from leaves (a), stem (b) and flowers (c) of V. patens. 
of the compounds found in leaves and steams was the same, but relative abundances in steam was higher. For leaves the majority monoterpene was $\alpha$-pinene, whereas in the stems was D-limonene.

The sesquiterpene compounds eluted from the column between 16.3 to 22.2 minutes. 19 compounds were identified in the leaves, 6 in the stems and 3 in the flowers. The results are shown in Table 2.

Sesquiterpenes present in the stems and flowers, are in the leaves as well, with the exception of zingiberene that is only present in stems. For those sesquiterpenes, variability is high and the most abundant is the Caryophillene with a relative abundance of $23.42 \%$. However, in the stems the most abundant sesquiterpene was the $\alpha$-bergamotene with $34.51 \%$ of relative abundance and in the flowers was the $\alpha$-humulene with $19.57 \%$ of relative abundance.

Caryophyllene compound and its oxide report properties of pharmacological interest as anti-inflammatory, antitumor, antibacterial, spasmolytic, anti-septic, anti-parasite against Trypanosoma cruzi and Leishmania brasi-

Table 2. Sesquiterpenes identified in volatile fraction of $V$. patens.

\begin{tabular}{|c|c|c|c|c|c|c|}
\hline \multicolumn{3}{|c|}{ leaves } & \multicolumn{2}{|c|}{ steams } & \multicolumn{2}{|c|}{ flowers } \\
\hline $\begin{array}{c}\text { rt } \\
\text { min }\end{array}$ & compound & $\%$ abund & compound & $\%$ abund & compound & $\%$ abund \\
\hline 16.01 & $\delta$-elemene & 1.38 & & & & \\
\hline 16.33 & $\alpha$-cubebene & 0.25 & & & & \\
\hline 17.04 & 1,4-cadinene & 3.46 & & & & \\
\hline 17.04 & & & $\alpha$-copaene & 0.78 & & \\
\hline 17.29 & $\beta$-bourbonene & 3.47 & & & & \\
\hline 17.43 & $\beta$-elemene & 0.31 & & & & \\
\hline 17.75 & & & zingiberene & 1.09 & & \\
\hline 18.17 & & & caryophyllene & 3.72 & & \\
\hline 18.20 & & 23.42 & & & caryophyllene & 8.30 \\
\hline 18.40 & germacrene-D & 0.47 & & & & \\
\hline 18.52 & $\alpha$-bergamotene & 4.55 & $\alpha$-bergamotene & 34.51 & & \\
\hline 18.66 & aromadendrene & 0.42 & & & & \\
\hline 18.78 & $\gamma$-muurolene & 0.27 & & & & \\
\hline 19.02 & & & $\alpha$-humulene & 1.94 & & \\
\hline 19.03 & $\alpha$-humulene & 4.96 & & & & \\
\hline 19.57 & & & & & $\alpha$-humulene & 19.57 \\
\hline 19.58 & $\gamma$-curcumene & 2.23 & & & & \\
\hline 19.69 & $\beta$-cubebene & 2.73 & & & & \\
\hline 19.74 & & & $\beta$-farnesene & 1.77 & & \\
\hline 19.84 & cis-muurola-3,5-diene & 0.34 & & & & \\
\hline 20.06 & bicyclogermacrene & 0.52 & & & & \\
\hline 20.24 & $\alpha$-farnesene & 0.23 & & & & \\
\hline 20.48 & $\alpha$-amorphene & 0.31 & & & & \\
\hline 20.68 & $\delta$-cadinene & 0.71 & & & & \\
\hline 22.14 & caryophyllene oxide & 0.49 & & & & \\
\hline
\end{tabular}


liensis [7] [8]; $\beta$ Ocimene as a powerful agent of tick [9]; $\alpha$-bergamotene compound as antibacterial and antioxidant [10]; insecticidal activity is reported for linalool [11]; and $\beta$-caryophyllene and $\alpha$-humulene present anti-fumigant activity [12].

Unfortunately there is no study on the volatiles of $V$. patens reported in the literature for comparison.

These results confirm the wealth in terpene compounds of $V$. patens from the Ecuadorian coast, for which Manzano et al., [13] [14] identified pentacyclic triterpenoids as major constituents of the species. The results are reported for first time in the species growing in Ecuador.

\section{Conclusion}

The fraction of volatile compounds from leaves, stems and flowers of $V$. patens is rich in sesquiterpene compounds, which are much more abundant in the leaves of the species together with monoterpene. A total of 20 sesquiterpenoids and 7 monoterpenoides in the samples studied are identified.

\section{Acknowledgements}

The authors thank SENESCYT for partial financial support of this work.

\section{References}

[1] Thorne, R. (2007) An Updated Classification of the Class Magnoliopsida (“Angiospermae”). The New York Botanical Garden, Bronx.

[2] Jeffrey, C. (2007) Compositae: Introduction with Key to Tribes. In: Kadereit, J.W. and Jeffrey, C., Eds., Families and Genera of Vascular Plants, Vol. VIII, Flowering Plants, Eudicots, Asterales, Springer-Verlag, Berlin, 61-87.

[3] Bremer, K. (1994) Asteraceae: Cladistics and Classification. Timber Press, Portland.

[4] Manzano Santana, P.I., García, M., Mendiola J., Fernández-Calienes, A., Orellana, T., Miranda, M., Peralta, E. and Monzote, L. (2014) In Vitro Anti-Protozoal Assessment of Vernonanthura patents Extracts. Pharmacologyonline, 1, 1-6.

[5] Manzano Santana, P.I., Miranda, M., Paz Robles, C., Abreu Payrol, J., Silva, M. and Hernández, V. (2012) Isolation and Characterization of the Hexane Fraction of the Leaves of Vernonanthura patens (Kunth) H. Rob. with Antifungal Activity. Cuban Journal of Pharmacy, 46, 352-358.

[6] Bohlmann, F., Jakupovic, J., Gupta, R., King, R. and Robinson, H. (1981) Allenic Germacranolides, Bourbonene Derived Lactones and Other Constituents from Vernonia Species. Phytochemistry, 20, 473-480. http://dx.doi.org/10.1016/S0031-9422(00)84169-2

[7] Carneiro, F.B., Júnior, I.D., Lopes, P.Q. and Macêdo, R.O. (2010) Varying the Amount of ß-Caryophyllene in the Essential Oil of Plectranthus amboinicus (Lour.) Spreng., Lamiaceae under Different Growing Conditions. Brazilian Journal of Pharmacognosy, 20, 600-606.

[8] Leite, N., Sobral-Souza, C., Albuquerque, R., Brito, D., Lavor, A., Alencar, L., Tintino, S., Ferreira, J. Figueredo, J., Lima, L., Cunha, F., Pinho, A. and Coutinho, H. (2013) In Vitro Cytotoxic Antiparasitic Activity of Caryophyllene and Eugenol against Trypanosoma cruzi and Leishmania brasiliensis. Cuban Journal of Medicinal Plants, 18, 522-528.

[9] Nchu, F., Magano, S. and Eloff, J. (2012) In Vitro Anti-Tick Properties of the Essential Oil of Tagetes minuta L. (Asteraceae) on Hyalomma rufipes (Acari: Ixodidae). Onderstepoort Journal of Veterinary Research, 79, E1-E5.

[10] Teixeira, B., Marques, A., Ramos, C., Nuno, R., Neng, J., Nogueira, J., Saraiva, A. and Nunes, M. (2013) Chemical Composition and Antibacterial and Antioxidant Properties of Comercial essential Oils. Industrial Crops and Products, 43, 587-595.

[11] Kessler, A. and Baldwin, I. (2001) Defensive Function of Herbivore-Induced Plant Volatile Emissions. Nature Science, 291, 2141-2144.

[12] Zoubiri, S. and Baaliouamer, A. (2012) GC and GC/MS Analyses of the Algerian Lantana Camara Leaf Essential Oil: Effect against Sitophilus Granaries Adults. Journal of Saudi Chemical Society, 16, 291-297. http://dx.doi.org/10.1016/j.jscs.2011.01.013

[13] Manzano Santana, P.I., Miranda, M., Payrol, J.A., Silva, M., Hernández, V. and Peralta, E. (2013) Gas Chromatography-Mass Spectrometry Study from the Leaves Fractions Obtained of Vernonanthura patens (Kunth) H. Rob. International Journal of Organic Chemistry, 3, 105-109. http://dx.doi.org/10.4236/ijoc.2013.32011

[14] Manzano, P.I., Miranda, M., Abreu-Payrol, J., Silva, M., Sterner, O. and Peralta, E.L. (2013) Pentacyclic triterpenoids with Antimicrobial Activity from the Leaves of Vernonanthura patens (Asteraceae). Emirates Journal of Food and Agriculture, 25, 539-543 
Scientific Research Publishing (SCIRP) is one of the largest Open Access journal publishers. It is currently publishing more than 200 open access, online, peer-reviewed journals covering a wide range of academic disciplines. SCIRP serves the worldwide academic communities and contributes to the progress and application of science with its publication.

Other selected journals from SCIRP are listed as below. Submit your manuscript to us via either submit@scirp.org or Online Submission Portal.
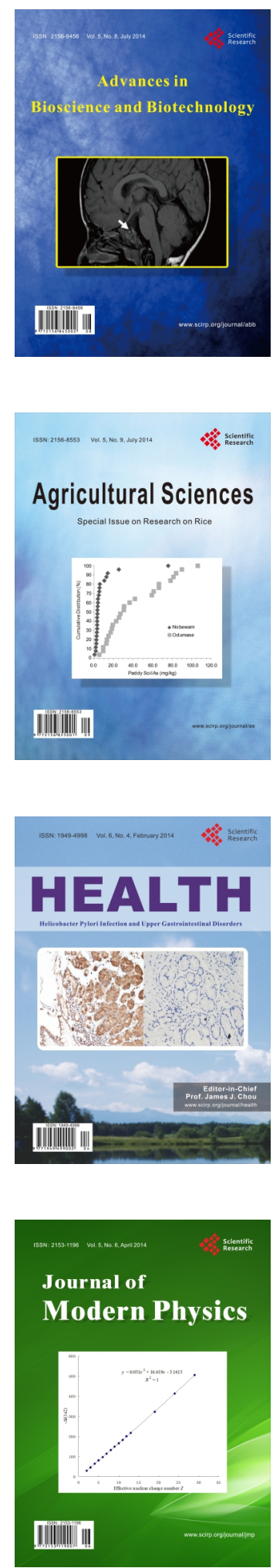
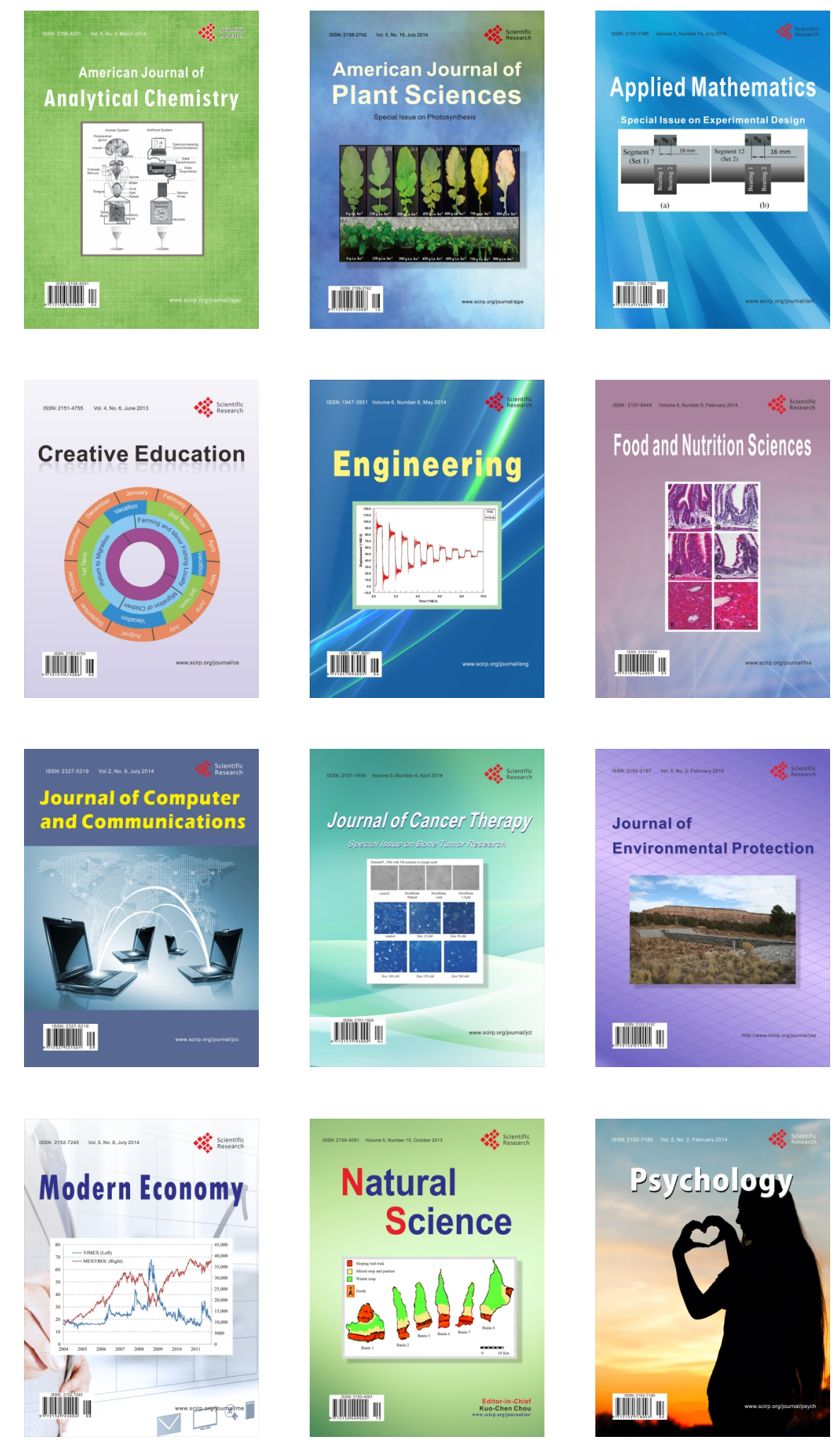